\title{
Computerised system for the continuous measurement of azygos venous blood flow
}

\author{
P C Hayes, D Terrace, I Peaston, I A D Bouchier, D Redhead, H M Brash
}

\begin{abstract}
A computer assisted apparatus for the continuous measurement of azygos blood flow is described. The system was validated in vitro and changes in flow which occur with respiration and Valsalva manoeuvre are illustrated. This apparatus allows real time inspection of flow values which enables changes in flow over short periods to be readily studied.
\end{abstract}

The development of portal hypertension in patients with chronic liver disease is responsible for the life threatening complications of variceal haemorrhage, ascites, and hepatic encephalopathy. Over the past 10 years there has been much interest in the use of drugs to reduce portal pressure and consequently the risk of variceal haemorrhage. Although portal hypertension has been recognised as an important factor in variceal bleeding, there is little correlation between the severity of the portal pressure and the risk of bleeding. ${ }^{12}$ While reducing the portal pressure to below $12 \mathrm{~mm} \mathrm{Hg}$, either by portasystemic shunt surgery or by drug treatment, reduces the risk of bleeding, there is little evidence that reductions in pressure, even though substantial, above this threshold reduce the risk of bleeding. ${ }^{3}$ The major risk factor for variceal haemorrhage seems to be the size of the oesophageal varices and it has been suggested that blood flow through the varices is a more important risk factor than portal pressure. ${ }^{+}$

The direct measurement of blood flow through oesophageal varices remains difficult to achieve but recently it has been proposed that measurement of blood flow in the azygos vein, into which the varices drain, reflects blood flow in the varices. Factors such as propranolol ${ }^{5}$ which cause a reduction in the azygos blood flow are believed to reflect a reduction in variceal flow which may be important in reducing the risk of variceal haemorrhage. Propranolol, which

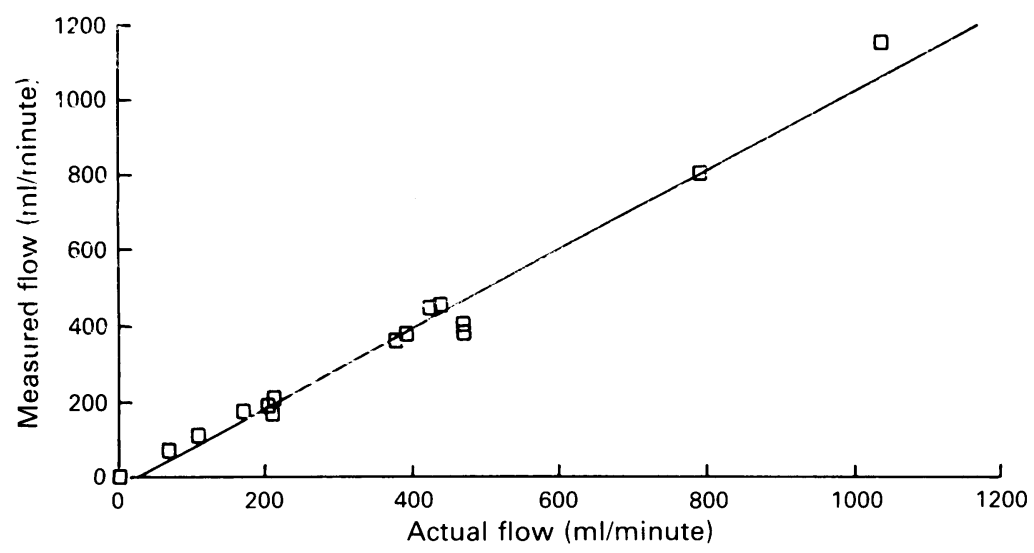

Figure 1 Correlation between computer calculated flow and actual flow. reduces both cardiac output and splanchnic blood flow, has been shown to reduce portal pressure in approximately $60 \%$ of patients with portal hypertension. ${ }^{5-9}$ Azygos blood flow, however, is reduced in all patients with portal hypertension who are treated with propranolol. ${ }^{58}$ The proportion of azygos blood flow which represents drainage through portal collaterals is unknown and likely to vary between patients. That much of the flow is probably from paraoesophageal vessels rather than flow through endoscopically visible varices, is supported by the observation of Cales et al that the correlation between variceal size and azygos flow is poor. ${ }^{9}$ However, since these vessels are interconnected it is reasonable to assume that changes in azygos flow reflect changes in variceal blood flow. Until direct measurements of variceal blood flow becomes possible, recording azygos blood flow remains an important tool for investigation of portal haemodynamics.

The original method described for measuring azygos blood flow employed a reverse thermodilution technique with calculations derived from a Wheatstone bridge used for flow measurements. This manual method is cumbersome requiring considerable use of calculators and is very time consuming, particularly if a pattern of rapid changes in flow is to be recorded, because each point on the curve requires separate calculation. We have developed a computerised system which allows continuous recording of azygos flow. This method allows real time measurement of rapid changes in collateral blood which may occur with respiration, exercise, and such physiological functions as a Valsalva manoeuvre.

In this paper we describe the methodology for continuous azygos blood flow measurement and its application under physiological conditions. Technical details of the computer interface and software will be published separately.

\section{Patients and methods}

Ten patients with biopsy proved chronic liver disease were studied, informed consent having been obtained. Patients were investigated in a fasted state and baseline measurements were recorded after resting supine for at least 15 minutes. In five subjects measurements were made before and during a Valsalva manoeuvre. Under radiological control a thermodilution catheter (Webster Lab Inc) was inserted into the azygos vein via the right femoral vein approach and positioned with its tip proximal to the arch of the vein. The injectate $(5 \%$ dextrose at room temperature (typically $22^{\circ} \mathrm{C}$ )) was infused at $50 \mathrm{ml} / \mathrm{minute}$ using a syringe pump (Harvard model 22 modified to meet BS 5724 standard). The signals from the internal (injectate) and 


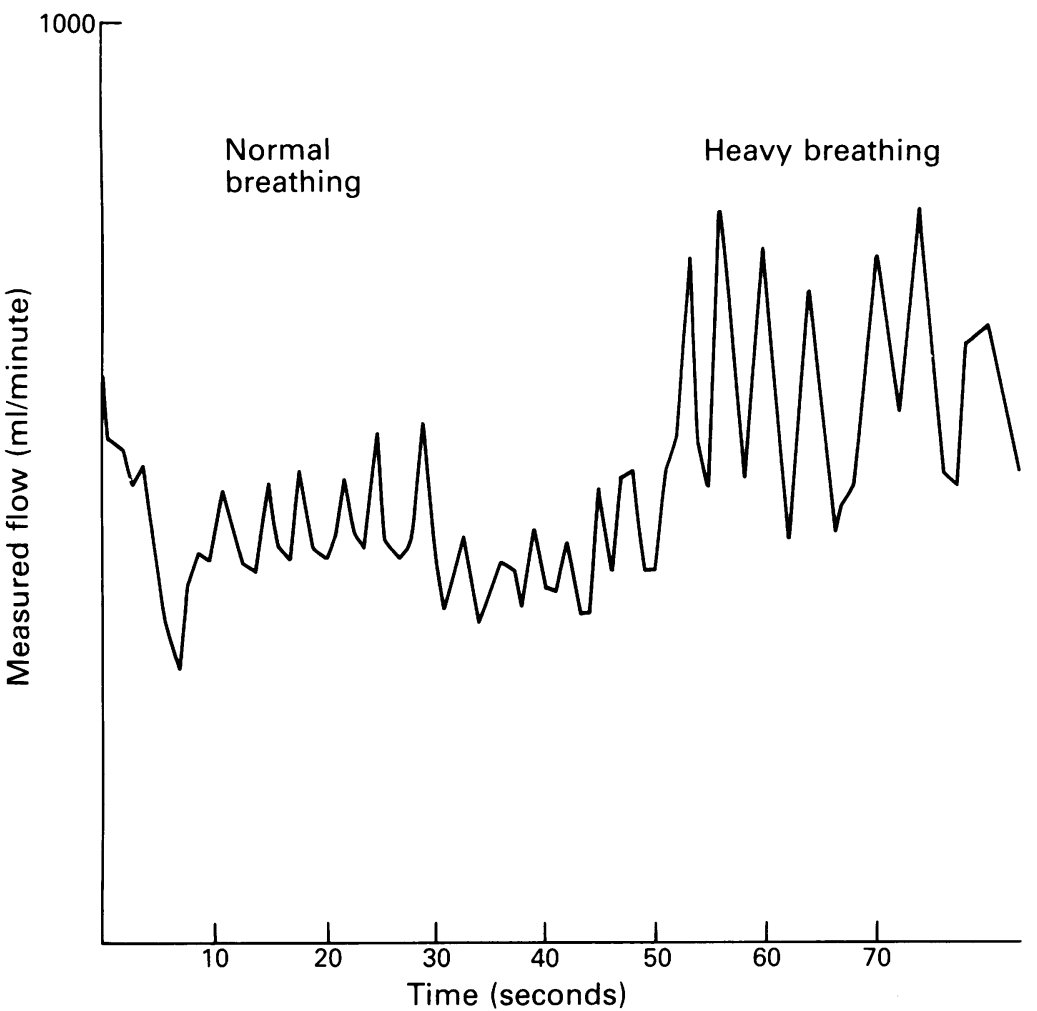

Figure 2: Illustration of the variation in azygos flow during normal (first half $)$ and heavy breathing (second half).

external (mixed blood) thermistors were transferred through a custom built interface (isolated to BS 5724 type CF) and processed in an IBM model PS2-286 microcomputer system to give real time values for blood flow using the algorithm described previously: ${ }^{10}$

$$
F_{B}=F_{I} \times c\left\{\frac{\triangle T_{I}}{\triangle T_{B}}-1\right\}
$$

where $F_{B}=$ blood flow rate; $F_{I}=$ indicator infusion rate; $\triangle T_{I}=$ change in injectate temperature; $\triangle T_{B}=$ change in blood temperature; and $c=$ constant dependent upon heating properties of blood + saline and the catheter manufacturer's constant.

A real time graphic display of blood flow was provided by the computer and the collection of data could be started and stopped as required at different stages of the tests. Specific events in the procedure could be designated using on-screen markers. Data were stored on hard and floppy disks for later analysis.

\section{N VITRO TESTING}

The apparatus described above was tested in

TABLE I Values of azygos blood flow (ml/minute) during quiet respiration, including mean values and peak and trough values during respiration

\begin{tabular}{|c|c|c|c|c|}
\hline \multirow[b]{2}{*}{ Patient } & \multirow[b]{2}{*}{ Mean } & \multicolumn{2}{|c|}{ Respiratory excursion } & \multirow{2}{*}{$\begin{array}{l}\text { Excursion } \\
\text { as\% of } \\
\text { mean }\end{array}$} \\
\hline & & Trough & Peak & \\
\hline 1 & $427 \cdot 1$ & $289 \cdot 8$ & $565 \cdot 2$ & $64 \cdot 5$ \\
\hline 2 & $198 \cdot 4$ & $145 \cdot 8$ & $250 \cdot 4$ & $52 \cdot 7$ \\
\hline 3 & 293.8 & $269 \cdot 9$ & $322 \cdot 5$ & $17 \cdot 9$ \\
\hline 4 & $472 \cdot 8$ & $383 \cdot 3$ & $551 \cdot 1$ & $35 \cdot 5$ \\
\hline 5 & $157 \cdot 2$ & $134 \cdot 3$ & $169 \cdot 5$ & $22 \cdot 4$ \\
\hline 6 & $264 \cdot 7$ & $172 \cdot 0$ & $365 \cdot 2$ & $73 \cdot 0$ \\
\hline 7 & $824 \cdot 3$ & $575 \cdot 3$ & 1253.6 & $82 \cdot 3$ \\
\hline 8 & $681 \cdot 2$ & $563 \cdot 4$ & $985 \cdot 8$ & $62 \cdot 0$ \\
\hline 9 & $969 \cdot 7$ & $768 \cdot 5$ & $1224 \cdot 4$ & $47 \cdot 0$ \\
\hline 10 & $210 \cdot 9$ & $156 \cdot 3$ & $355 \cdot 0$ & $94 \cdot 2$ \\
\hline Mean (SD) & $450 \cdot 0(284 \cdot 7)$ & $345 \cdot 9(221 \cdot 1)$ & $604 \cdot 3(404 \cdot 0)$ & $57 \cdot 4$ \\
\hline
\end{tabular}

TABLE II Values of azygos blood flow ( $\mathrm{ml} /$ minute $)$ with the Valsalva manoeuvre in subjects before (baseline), after initial expiration against the closed glottis (peak flow), and nadir during continued attempted expiration (trough flow)

\begin{tabular}{llcl}
\hline Patient & Baseline flow & Peak flow & Trough flow \\
\hline 1 & $422 \cdot 9$ & $832 \cdot 5$ & $398 \cdot 7$ \\
2 & $198 \cdot 4$ & $300 \cdot 7$ & $83 \cdot 7$ \\
3 & $287 \cdot 0$ & $371 \cdot 8$ & $131 \cdot 2$ \\
4 & $464 \cdot 8$ & $1328 \cdot 1$ & $231 \cdot 7$ \\
5 & $156 \cdot 7$ & $358 \cdot 6$ & $24 \cdot 3$ \\
Mean (SD) & $306 \cdot 0(135 \cdot 2)$ & $638 \cdot 3(440 \cdot 7)$ & $173 \cdot 9(146 \cdot 8)$ \\
\hline
\end{tabular}

vitro using an adjustable, recirculating, flow of water at $37^{\circ} \mathrm{C}$ from a temperature controlled bath over a range of flow rates from 70 to $1200 \mathrm{ml} /$ minute.

\section{Results}

The apparatus tested in vitro was both accurate (Fig 1) and reproducible (coefficient of variation $2 \cdot 8 \%$ ). Measurements of flow using this system in vivo were comparable with those previously reported (Tables I and II) ${ }^{89}$

Continuous measurement of azygos flow in patients showed significant changes in variceal flow with respiration (Table I). Respiration resulted in changes in azygos blood flow of approximately $60 \%(17 \cdot 9-94 \cdot 2 \%)$ increasing with inspiration and falling with expiration (Fig 2). These changes were more obvious with deep breathing, with the overall azygos flow increasing (Fig 2). Valsalva manoeuvres in these subjects produced a characteristic change in flow, with an approximately $100 \%$ increase during inspiration and initial expiration against the closed glottis followed by a rapid fall in flow, which in some patients approached zero, followed by a return towards resting flow rates towards the end of the manoeuvre (Figs 3 and 4; Table II). The extent of the increase in flow on inspiration and its fall with the Valsalva manoeuvre varied from individual to individual (Table II).

\section{Discussion}

Clearly identifiable risk factors for bleeding from oesophageal varices remain elusive. Currently, the most important factor seems to be the size of the varix and possibly other endoscopic features, such as red spots. ${ }^{+}$Although it has been recognised that azygos flow correlates poorly with variceal size, drugs which reduce bleeding reduce azygos flow even when not influencing portal pressure..$^{8-12}$ Methods which have been described for measuring azygos flow $^{89}$ suffer from the practical limitation that the manual measurement and calculation of flow for each data point denies the user a real time view of the flow changes occurring during a manoeuvre. The great advantage of the new system which we have developed is that continual flow measurements are possible.

We have shown the apparatus described in this paper to be accurate using an in vitro system and to be capable of providing flow measurements at the rate of 10 per second to allow continuous measurement of azygos blood flow.

We have shown that considerable changes in azygos flow occur during respiration and we believe that this reflects changes in oesophageal 


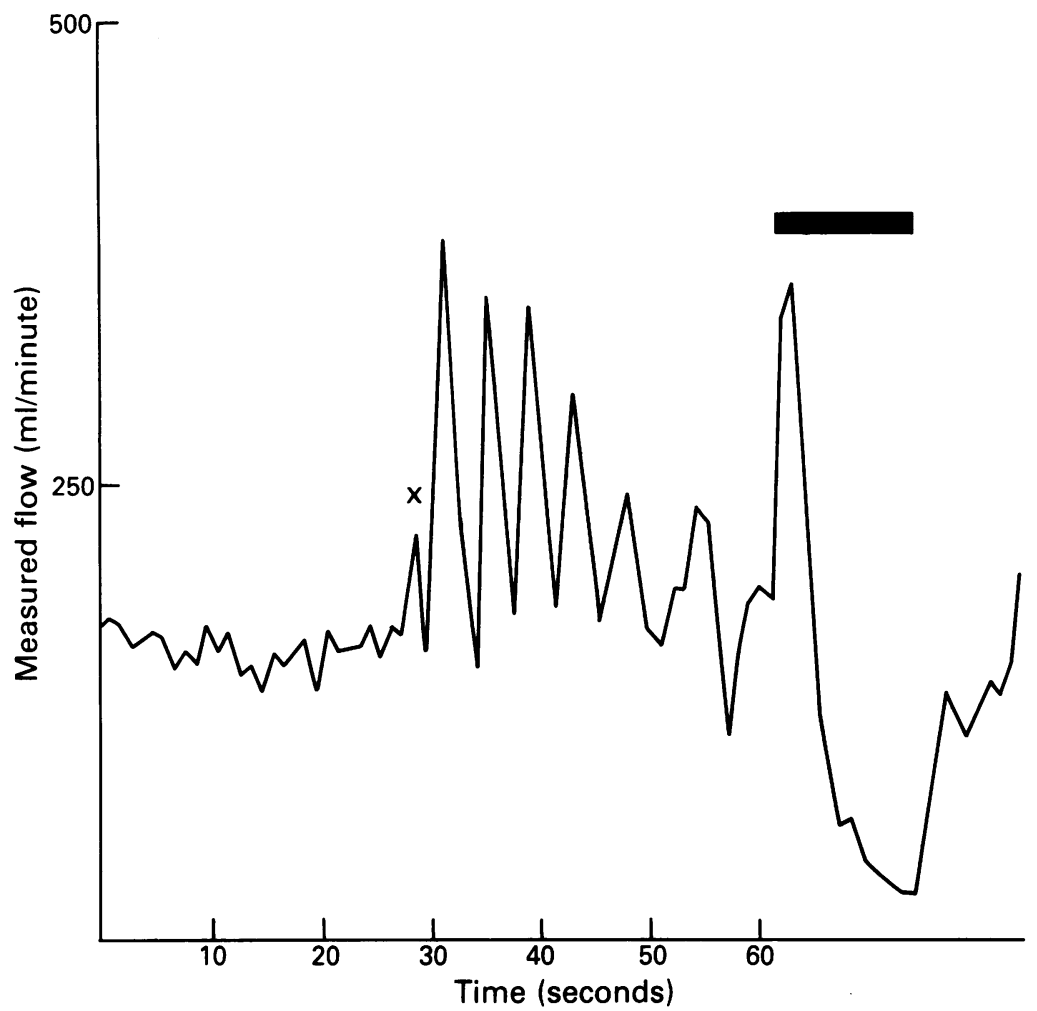

Figure 3: Illustration of changes in azygos flow with heavy breathing $(x)$ and during Valsalva manoeuvre (continuous bar).

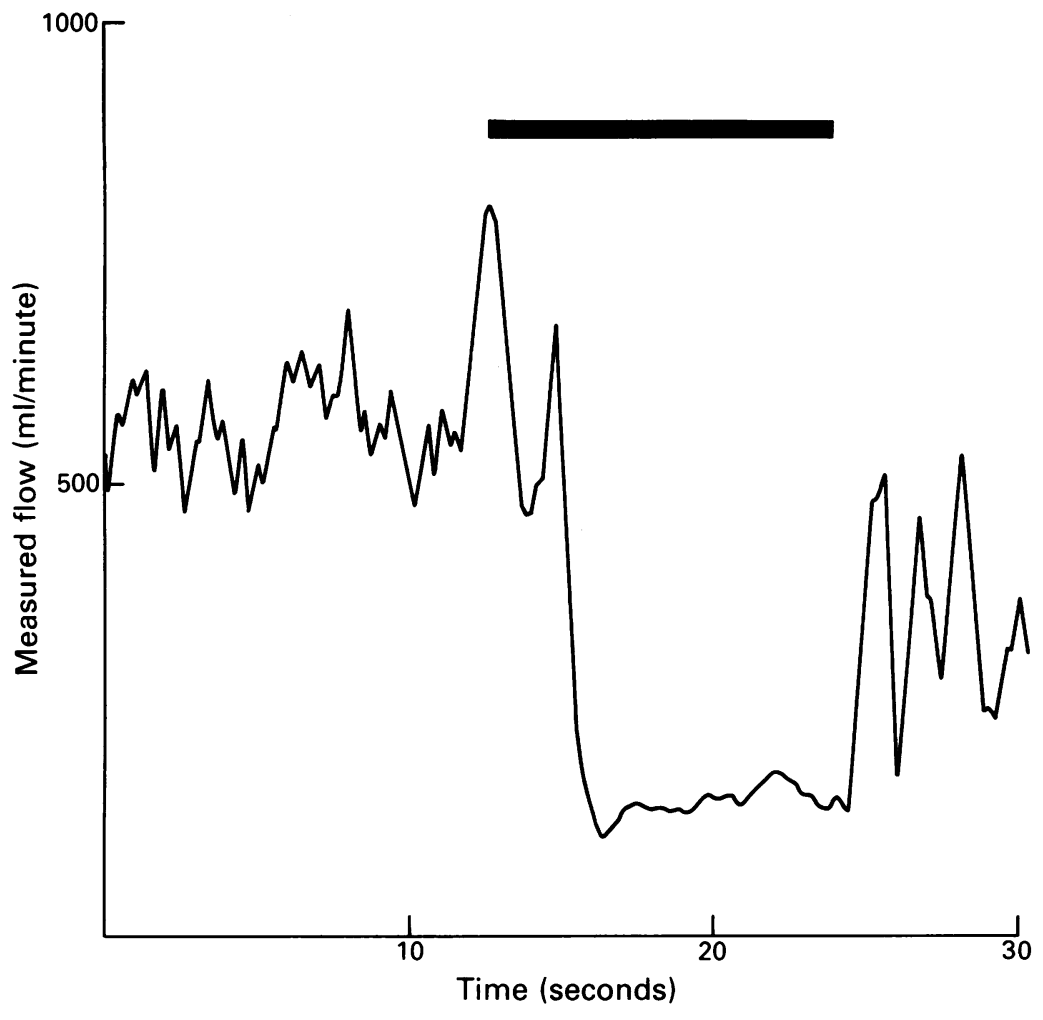

Figure 4: Persistent reduction in azygos flow during Valsalva manoeuvre (continuous bar).

portasystemic collateral flow of a similar proportion, although of lower absolute flow rates. We believe that the observations in this study are of importance in increasing our understanding of the pathophysiology of variceal haemodynamics and may also provide insight into risk factors for variceal haemorrhage. We have preliminary data indicating that some patients may have bled after vigorous strenuous exercise such as moving furniture when Valsalva manoeuvres would have been performed. The data from this study provides strong evidence of why haemorrhage should have occurred. We believe the variation in flow during respiration represents changes in azygos venous resistance, as similar changes in portal pressure do not occur. Measurement of variceal pressure during Valsalva manoeuvre shows no consistent change, ${ }^{13}$ which again supports the hypothesis that it is changes in resistance that are important in producing variation in flow during such physiological manoeuvres. This ability of resistance to change with respiration may be a factor of importance in variceal haemodynamics and deserves further examination.

The computerised system that we have described readily shows the wide variation that occurs in azygos blood flow during respiration and emphasises that single readings should not be considered representative of an individual's oesophageal collateral blood flow. We believe that this system is an advance over existing methods both in terms of increased precision and the ability to undertake real time dynamic haemodynamic investigations of patients with portal hypertension.

We would like to thank Boehringer Mannheim and Edinburg University for financial help with developing this system and M Vanessa Campbell for her secretarial skill.

1 Reynolds TB. Promises! promises! hemodynamics and portosystemic shunts. N Englf Med 1974; 290: 1484-5.

2 Valla D, Jiron MI, Poynard T, et al. Failure of haemodynamic measurements to predict recurrent gastrointestinal bleeding in cirrhotic patients receiving propranolol. $\mathcal{F}$ Hepatol 1987 ; 5. $144-8$.

3 Gitlin N. Portal hypertension. Curr Opin Gastroenterol 1990; 6: $370-5$.

4 Sauerbruch T, Wotzka R, Kopcke W, et al. Prophylactic sclerotherapy before the first episode of variceal haemorrhage in patients with cirrhosis. N Engl F Med 1988; 319:

5 Lebrec D, Poynard T, Hillon T, Benhamou JP. Propranolol for prevention of recurrent gastrointestinal bleeding in patients with cirrhosis: a controlled trial. $N$ Engl f Med 1981; 305: 1371-4.

6 Mills PR, Wray AP, Farrar DA, Russell RI, Lorimer AR, Carter DC. Comparison of three adrenoceptor blocking agents in patients with cirrhosis and portal hypertension. Gut 1984; 25: 73-8.

7 Westaby D, Bihari D, Gimson AES, et al. Selective and non selective beta-blockade in the reduction of portal hypertension in patients with cirrhosis and portal hypertension. Gut sion in patients

8 Bosch J, Masty R, Kravetz D, et al. Effect of propranolol on azygos venous blood flow and hepatic and systemic haemodynamics in cirrhosis. Hepatology 1984; 4: 1200-5.

9 Cales P, Braillon A, Giron MI, et al. Superior portosystemic collateral circulation estimated by azygos blood flow in patients with cirrhosis. Lack of correlation with oesophageal varices and gastrointestinal bleeding: effect of propranolol. f Hepatol 1984; 1: 37-46.

10 Ganz W, Tamura K, Marcus HS, et al. Measurement of coronary sinus blood flow by continuous thermodilution in man. Circulation 1971; 44: 181-95.

11 Hayes PC, Davis JM, Lewis JA, Bouchier IAD. Meta-analysis of value of propranolol in prevention of variceal haemorrhage. Lancet 1990; 336: $153-6$.

12 McCormick PA, Dick R, Siringo S, et al. Octreotide reduces azygos blood flow in cirrhotic patients with portal hypoazygos blood flow in cirrhotic patients with portal

13 Hosking SW, Robinson P, Johnson AG. Effect of valsalva's manoeuvre and hyoscine butylbromide on the pressure manoeuvre and hyoscine butylbromide on the pressure gradient 